\title{
Bilateral chronic central serous chorioretinopathy associated with IGRA latent tuberculosis infection: A case report and review
}

\author{
A Scott Kavanaugh, Bilal A Shaukat, Jennifer T Pan and Marlyn P Langford* \\ Department of Ophthalmology, Louisiana State University Health Sciences Center, Shreveport, LA, 71130 USA
}

\begin{abstract}
A 37-year-old Indian male presented with a 3-year history of right eye blurred vision. Bilateral ophthalmic examinations revealed shallow, oval areas of macular subretinal fluid containing hypopion-like precipitates and central neurosensory retinal detachments with focal early-stage fluorescein leakage consistent with central serous chorioretinopathy (CSCR). Inadequate response to Eplerenone prompted reassessment yielding a positive BCG vaccine history. Latent tuberculosis infection (LTBI) was diagnosed by a positive interferon- $\gamma$ response assay (IGRA) in the absence of pulmonary symptoms. Rifampin alone yielded only modest bilateral visual acuity increases and subretinal fluid decreases. Right eye focal macular laser was performed to stabilize vision with modest subretinal fluid decrease, but peripheral retinal lesions were noted on follow up. The patient has been unavailable for follow up evaluation and supportive anti-tuberculosis treatment (ATT) to date. The unresponsiveness to anti-corticosteroid medications in our case of CSCR secondary to LTBI, the reported detection of Mycobacterium tuberculosis DNA in CSCR subretinal fluid, and the resolution CSCR post ATT in 3 previous CSCR secondary to LTBI cases support a possible association of CSCR and LTBI. To our knowledge this is the fourth case of chronic CSCR in a patient with LTBI.
\end{abstract}

\section{Introduction}

Central serous chorioretinopathy (CSCR) is a common visionthreatening eye disease of unknown etiopathogenesis without a universally accepted treatment [1-4]. Acute CSCR occurs most often, is usually unilateral, and generally resolves within 3 months, but up to $50 \%$ of CSCR cases, generally among middle-aged males, become chronic with frequent recurrences resulting in poor vision [2-4].

CSCR usually presents as a well-circumscribed, serous detachment of the neurosensory retina from the retinal pigment epithelium (RPE) due to subretinal fluid (SRF) accumulation from a single or multiple leakage points $[5,6]$. CSCR risk factors include male gender, hypertension, type-A personality, stress, pregnancy, corticosteroids, psychopharmacologic medication, autoimmune disease, sleeping disturbance, and Helicobacter pylori infection [7-10].

We report a case of chronic CSCR in a middle-aged adult male diagnosed with asymptomatic latent $M$. tuberculosis infection (LTBI). A literature review of the three adult cases of CSCR secondary to LTBI supports an association of CSCR and LTBI. The CSCR associated with LTBI in our case was unresponsive to anti-corticosteroid therapies.

\section{Case report}

A 37-year-old, healthy Indian male presented with a 3-year history of blurred vision OD. His best-corrected visual acuity (BCVA) was 20/50 OD and 20/25 OS (no improvement with pinhole or refraction). External eye $s$ and intraocular pressures were normal. Fundus examinations showed shallow, round areas of elevation involving the fovea containing white exudates that settled inferiorly in a dependent fashion in both eyes (Figures 1A and 1B). Notably, focal areas of leakage with eventual expansion of the leakage and late pooling were detected by fluorescein fundus angiography (FFA) (Figures 1C and 1D). Bilateral retinal detachments from the RPE with similar SRF volumes (10.69 $\mathrm{mm}^{3} \mathrm{OD}$ and $10.03 \mathrm{~mm}^{3} \mathrm{OS}$ ) and highest retinal prominence (HRP: $583 \mu \mathrm{m}$ OD and $498 \mu \mathrm{m}$ OS) were confirmed by optical coherence tomography (OCT) scans (Figures $1 \mathrm{E}$ and $1 \mathrm{~F}$ ). A diagnosis of bilateral chronic CSCR was made and the patient was placed on 6-month course of Eplerenone (50 mg daily) [11].

Slight improvement in BCVA of 20/40 OD and 20/20 OS was noted after 6 months, but fundus evaluation remained unchanged with only slight decreases in SRF volume $\left(-0.2 \mathrm{~mm}^{3} \mathrm{OD}\right.$ and $\left.-0.5 \mathrm{~mm}^{3} \mathrm{OS}\right)$ and HRP $(-40 \mu \mathrm{m}$ OD and $-40 \mu \mathrm{m}$ OS $)$. The Eplerenone treatment was discontinued due to lack of marked clinical improvement. Patient reassessment elicited a history of bacillus Calmette-Guérin vaccination in India. A positive interferon- $\gamma$ response assay (IGRA; T-spot test measures $\mathrm{T}$ cells response to $M$. tuberculosis antigens) and areas of retinal whitening prompted a suspicion of tuberculosis (TB) chorioretinitis. The patient had no clinical symptoms of active TB.

A systemic re-evaluation by Internal Medicine found no radiological symptoms of active TBI were detected. A diagnosis of LTBI was made based upon the positive IGRA and absence of pulmonary symptoms [12]. The patient was started on rifampin $300 \mathrm{mg}$ twice a day

*Correspondence to: Marlyn P. Langford, $\mathrm{PhD}$, Department of Ophthalmology, Louisiana State University Health Sciences Center, 1501 Kings Hwy./PO Box 33932, Shreveport, LA 71130 USA; E-mail: mlangf@lsuhsc.edu

Key words: bacterial infection, interferon- $\gamma$, mineralocorticoid receptor antagonist, rifampin

Received: November 03, 2020; Accepted: December 09, 2020; Published: December 14, 2020 

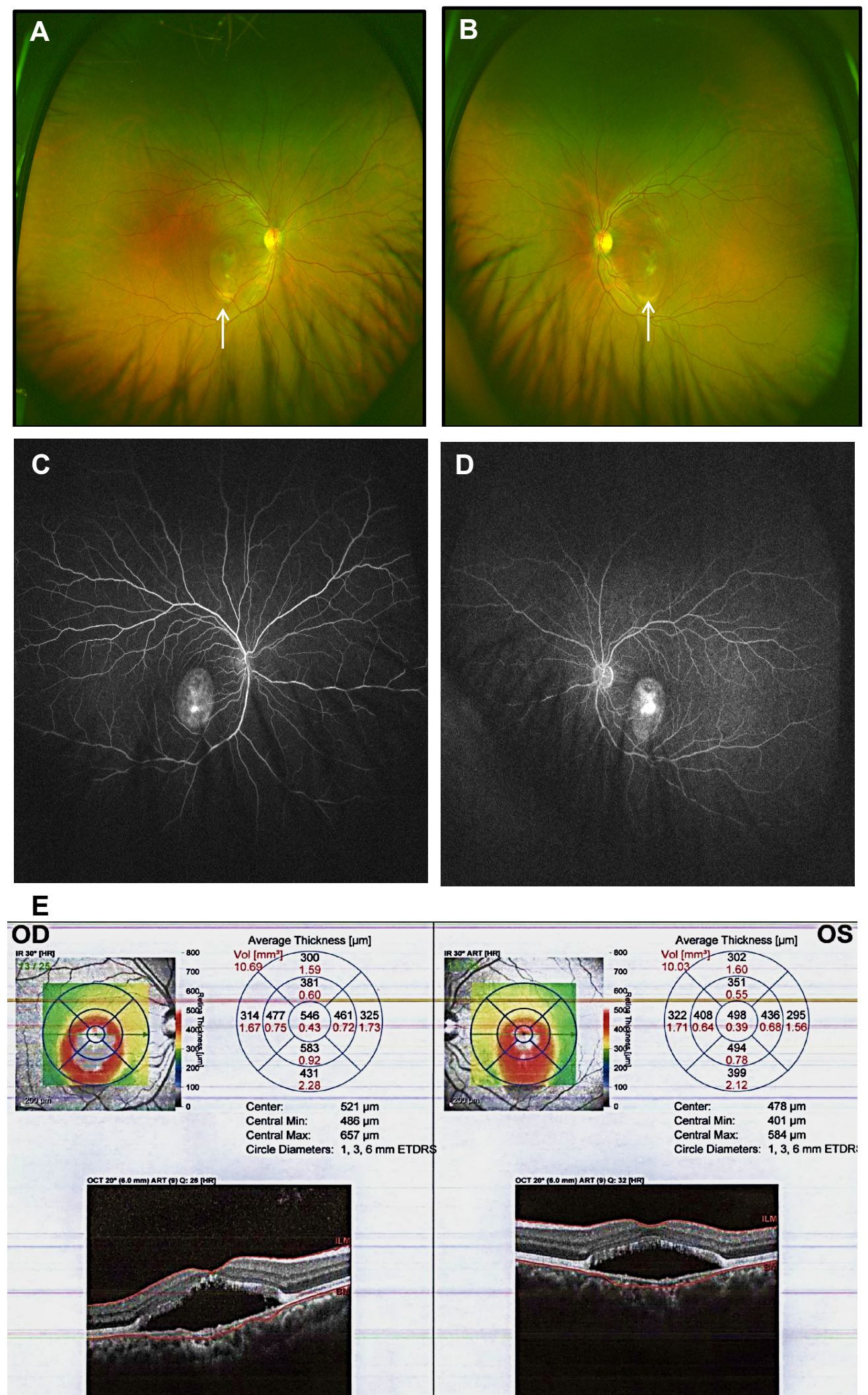

Figure 1. Fundus photographs of the right (A) and left (B) eyes at presentation showing symmetric bilateral sub-retinal fluid spaces with fluffy exudate forming a boat-like pattern (arrows) without any signs of vasculitis or inflammation. Fundus fluorescein angiographies (FFA) of the right (C) and left (D) eyes showing leakage in a smoke stack pattern. (E) OCT images of the right (OD) and left (OS) eyes showing serous detachment of RPE from neurosensory retina 
as a treatment option for LTBI and CSCR [4]. After the total 6-month course of rifampin, the BCVA was 20/40 OD and 20/20 OS, and there were only slight reductions in SRF volumes $\left(-0.61 \mathrm{~mm}^{3}\right.$ and $-0.1 \mathrm{~mm}^{3}$ OS) and HRP ( $-46 \mu \mathrm{m}$ OD and $-8 \mu \mathrm{m}$ OS). Based upon minimal SRF improvement, the rifampin was discontinued and focal macular laser (FML) was performed around the areas of presumed subretinal fluid leakage. FML was repeated 4 months later. The BCVA (20/40 OD and 20/20 OS) and OCT findings have remained stable, but dilated fundus exams detected some new smaller inferonasal white spot/lesion compared to previous exam. The current medical plan upon his return to clinic is to evaluate his ocular and TB status and offer ATTx4.

\section{Review of cases}

The review of the 3 previously reported cases [13-15] and our case of CSCR secondary to LTBI was significant for patients being middleaged adult males from diverse geographic, cultural/racial backgrounds (Table 1). The clinical histories were significant for prolonged reduction in visual acuity (blurred vision) with two cases presenting with metamorphopsia. Fundus exams revealed bilateral areas of SRF in three cases. FFA assessment noted early and late multi-focal or diffuse hyperfluorescence in the macular area. Suspicion of TB infections in these cases were based on family history, travel from endemic area, ethnic background, and history of TB infection. Presumptive LTBI diagnoses were made based on a supportive history and a positive IGRA (T-spot test) in the absence of active pulmonary disease. Complete or significant improvement was observed in 3 cases given a ATTx4 (isoniazid, rifampin, ethambutol, and pyrazinamide) with one of the aforementioned patients maintained on rifampin. Our case has not received ATT, but rifampin alone had little therapeutic effect.

\section{Discussion/Conclusion}

The current number of clinical cases and basic research results support latent $M$. tuberculosis infection as a possible risk factor for
CSCR. Accordingly, our case and the 3 previously reported cases of CSCR secondary to LTBI occurred in middle-aged males consistent with the higher intraocular TB incidence in this age-sex group [1]. Prompt CSCR improvement following ATT (therapy is based in antituberculosis drugs and corticosteroids) in 3 cases [13-15], suggests eradication of LTBI was associated with resolution of the CSCR. The resolution of CSCR post ATT suggests retinal M. tuberculosis infection contributes to CSCR symptoms. In this regard, M. tuberculosis DNA has been detected in the SRF of patients with tuberculosis infection $[16,17]$ and RPE cells have been shown to survive $M$. tuberculosis infection suggesting RPE cells can serve as an intraocular reservoir for M. tuberculosis [18, 19]. The mechanism of the CSCR secondary to LTBI is unknown, but may be due in part to pro-apoptotic and/ or pro-inflammatory effects of the $M$. tuberculosis infection [20,21]. Concomitantly, the duration and recurrence frequency of CSCR associated with $H$. pylori infection $[8,10,22]$ is reduced by triple-drug therapy eradication of $H$. pylori [10]. The mechanism(s) responsible for the CSCR associated with $H$. pylori infection is unknown, but the CSCR appears to be a RPE disease with a general choroidal microcirculation involvement [23]. The reported CSCR resolution post antibiotic eradication of $H$. pylori and ATT treatment of LTBI suggests the consideration of bacteria-induced cytopathogenic mechanisms [24].

The diagnosis of LTBI in an immunocompetent person with asymptomatic disease is difficult, but important to TB prevention. A presumptive ocular TB diagnosis is supported by the combination of the ophthalmological inflammatory pattern and confirmatory tests for TB infection $[25,26]$. LTBI diagnosis requires a positive test for infection and a negative evaluation for active disease. A diagnosis of CSCR secondary to LTBI, in the reported cases, was made after systemic reevaluation due to worsening retinal disease with or without treatment. The LTBI diagnosis required solicitation of an accurate past medical history and confirmatory tests. In our case, failed Eplerenone treatment for bilateral CSCR prompted patient re-evaluation, which ultimately

Table 1. Review of CSCR secondary to latent tuberculosis (LTBI) cases

\begin{tabular}{|c|c|c|c|}
\hline Cases & Presentation, Past Medical History, Ocular Findings, Diagnosis & $\begin{array}{l}\text { TB Diagnosis and } \\
\text { Treatments }\end{array}$ & Final Outcome \\
\hline $\begin{array}{l}32 \text { yo Angolian } \\
\text { Afro-Caribbean } \\
\text { Male [13] }\end{array}$ & $\begin{array}{l}\text { Presented: BCVA } 6 / 6 \text { OD \& 6/5 OS. PMH: 4-mo history OD blurred vision and metamorphopsia. } \\
\text { Ocular Exam: FFA early multifocal leakage points; OCT showed multiple macular RPE detachments } \\
\text { Dx: idiopathic RPE detachment; } \\
2 \text { mo later progressive OD VA loss ( } 6 / 60 \text { progressing to } 1 / 60 \text { over next wk). Funduscopic exam showed } \\
\text { serous macular detachment. Dx: multi-focal CSCR } \\
\text { Additional labs ordered based upon ethnic origin, large CSR, atypical FFA findings }\end{array}$ & $\begin{array}{l}\text { Strongly }+ \text { T-spot test, ethnic } \\
\text { background; no other clinical } \\
\text { or radiological signs } \\
\text { Dx: presumed LTBI. } \\
\text { Tx: ATT }\end{array}$ & $\begin{array}{l}\text { Vision improve and SRF } \\
\text { completely resolved after } 6 \mathrm{wk} \\
\text { post ATT }\end{array}$ \\
\hline $\begin{array}{c}54 \text { yo Hispanic } \\
\text { Venezuela Male } \\
{[14]}\end{array}$ & $\begin{array}{l}\text { Presented: BCVA } 20 / 70 \text { OD \& } 20 / 25 \text { OS. PMH: } 1 \text { yr Hx of OD blurred vision; Myopia and } \\
\text { presbyopia, asymptomatic post ATTx } 3 \text { for TB } 3 \text { yr ago } \\
\text { Ocular Exam: Bilateral mid-periphery and macular pigmentary changes; early \& late broad FFA } \\
\text { hyperfluorescent areas with few leakage points. OCT revealed SRF OD/ foveal attenuation OS. Dx: } \\
\text { chronic CSCR } \\
\text { Re-evaluation prompted by Hx and clinical presentation: }\end{array}$ & $\begin{array}{l}+ \text { PPD, +Quantiferon-Gold, } \\
\text { and +chest x-ray consistent } \\
\text { with distant pulmonary TB } \\
\text { Dx: distant LTBI. } \\
\text { Tx: ATT } \\
\text { Maintenance Rifampin }\end{array}$ & $\begin{array}{l}\text { Recurrent SRF OD } \\
\text { after ATT discontinued } \\
\text { ATT restarted } \\
\text { Resolution of SRF } \\
\text { Rifampin monotherapy } \\
\text { Stable no recurrence }\end{array}$ \\
\hline $\begin{array}{c}32 \text { yo Indian } \\
\text { Male [15] }\end{array}$ & $\begin{array}{l}\text { Presented: BCVA 6/24 OD \& 6/12 OS with metamorphopsia. PMH: No history of medication use } \\
\text { or allergies } \\
\text { Ocular Exam: OD serous elevation of macular area with RPE detachment by OCT. FFA showed focal } \\
\text { areas late stage hyperfluorescence } \\
\text { Dx: bilateral CSCR; Tx: Bilateral focal laser photocoagulation. } \\
\text { Recurrence } 2 \text { yrs later OD vision loss with SRF elevation from new leakage sites; } \\
\text { Tx: AZM. } 1 \text { yr later: } \\
\text { Recurrence with macular edema and subretinal fluid new leakage sites } \\
\text { Tx: AZM; } \\
\text { Re-evaluation prompted by no improvement and family history of TB }\end{array}$ & $\begin{array}{l}\text { Family Hx; from India an } \\
\text { endemic area, +PPD, +Chest } \\
\text { X-ray suggestive of TB. } \\
\text { Dx: presumed TBI } \\
\text { Tx: ATT } \\
\text { Tx: AZM x2; Bilateral focal } \\
\text { laser }\end{array}$ & $\begin{array}{l}\text { VA improved to normal post } \\
\text { laser } \\
\text { CSCR Recurrence } \\
\text { Improved VA } 2 \text { wk after ATT } \\
\text { and laser. } \\
\text { No complaints at } 9 \text { mon }\end{array}$ \\
\hline $\begin{array}{l}37 \text { yo Telugu- } \\
\text { Indian Male } \\
\text { (Current case) }\end{array}$ & $\begin{array}{l}\text { Presented: BCVA } 20 / 50 \text { OD } 20 / 25 \text { OS. PMH: } 3 \text {-yr Hx of OD blurred vision. } \\
\text { Ocular Exam: FFA revealed bilateral pin point fluorescein leakage. Bilateral SRF/RD } \\
\text { Dx: bilateral CSCR/RD } \\
\text { Tx: Eplerenone stopped after } 6 \text { mon due to no improvement } \\
\text { Re-Evaluation prompted by failed treatment and history of BCG vaccination }\end{array}$ & $\begin{array}{l}\text { BCG vaccination, } \\
\text { +Quantiferon test. } \\
\text { Dx: presumed LTBI } \\
\text { Tx: Rifampin alone for } 6 \text { mon } \\
\text { then discontinued } \\
\text { Tx: FML }\end{array}$ & $\begin{array}{l}\text { BCVA of } 20 / 40 \text { OD and } 20 / 20 \\
\text { OS } 6 \text { mon } \\
\text { No improvement } \\
\text { FA and OCT improvement } \\
\text { at } 4 \text { wk } \\
\text { Stable VA (20/40 OD), new } \\
\text { FFA spots OD }\end{array}$ \\
\hline
\end{tabular}


led to LTBI confirmation based upon a positive IGRA test. A confirmed LTBI diagnosis is supported by a positive IGRA even in a CSCR patient immunized with BCG vaccine, as in the current case. The standard skin test can show false positive results in BCG vaccinated patients. A definitive diagnosis of ocular TB is established by the combination of clinical ocular inflammatory signs and the demonstration of the Mycobacterium in ocular samples. Unfortunately, ocular TB may occur in patients with asymptomatic TB disease and remain undiagnosed due to the absence of ocular biopsies.

The CSCR secondary to LTBI cases presented with a longstanding history of diminished visual acuity with or without metamorphopsia. Single or multifocal retinal lesions were characterized by SRF in the macular area between the RPE and the neurosensory retina. In our case, areas of SRF with precipitate and focal "smoke stack" leakage points were identified in both eyes. The smoke stack leakage pattern occurs in $7-11 \%$ of primary CSCR eyes and $80 \%$ of recurrent leakage points generally arise within $1 \mathrm{~mm}$ of the primary leakage point in CSCR cases $[5,6]$. The appearance of new leakage points was noted in our case after failed rifampin treatment; entertaining the possibility that the $M$. tuberculosis was rifampin resistant. M. tuberculosis resistant to rifampin, isoniazid, and multiple drugs can arise quickly and should be considered in TB unresponsive to ATT [27]. M. tuberculosis was not isolated, thus rifampin resistance could not confirmed by Xpert MTB/ RIF assay [28].

CSCR treatment options, including photocoagulation laser therapy, have been investigated and refined due to complications such as scotoma, choroidal neo-vascularization, and persistent metamorphopsia [1,29]. More recently, clinical investigations with oral medications for acute and chronic CSCR have been reported $[4,11,14,30]$. Our CSCR associated LTBI case did not resolve with Eplerenone (a mineralocorticoid-specific receptor antagonist) or rifampin (potent inducer of cytochrome P450 shown to reduce circulating endogenous and exogenous steroids levels [31], in contrast to idiopathic CSCR [11,30]. Our support for rifampin therapy was predicated upon its beneficial effects against chronic CSCR $[4,14,30]$ and anti-mycobacterial action (inhibits protein synthesis by blocking DNA-dependent RNA synthesis) [32]. Ultimately, FML (focal macular laser) was applied to the right eye as warranted following unsuccessful rifampin therapy to help preserve vision.

In conclusion, CSCR has been associated with a number of risk factors and treated in a number of different ways with mixed results. The subset of CSCR patients diagnosed with a LBTI by skin test or IGRA may fail anti-corticoid therapy and should be offered ATT to eradicate the TB infection and provide the possibility of visual acuity improvement and CSCR resolution.

\section{Acknowledgements}

The authors recognize Julio Vega (MS3) for his assistance in patient data collection.

\section{Declarations}

\section{Ethics approval and consent to participate}

The study was approved by the LSU HRPP/Internal Review Board as non-research patient care (No. 00000918). The investigation was performed according to the ethical standards set forth in the World Medical Association Declaration of Helsinki. Written informed consent to report this case and publish the clinical data results was obtained from the patient. The research was deemed non-human research by the Institutional Review Board.

\section{Consent for publication}

Informed written consent for publication of this case was obtained from the patient.

\section{Availability of data and materials}

The clinical data presented in the article are available on request from the corresponding author, [ASK]. The data are not publicly available, but are available to all requests approved by the LSU Health Sciences Center HRPP/Internal Review Board.

\section{Competing interests}

The authors declare that they have no competing financial or conflicts of intellectual interests. In accordance with Taylor \& Francis policy and my ethical obligation as a researcher, I am reporting that I nor the co-authors have financial and/or business interests in a company that may be affected by the research reported in the enclosed paper. I have disclosed those interests fully to Taylor \& Francis.

\section{Funding}

The research was supported in part by an unrestricted grant from Alcon for the LSU Medical School Ophthalmology Resident Continuing Medical Education. The sponsors had no part in data collection, data interpretation, or management of the case.

\section{Authors' contributions}

BAS and MPL were major contributors to the conception, design and drafting of the manuscript. BAS, JTP and ASK acquired, analyzed and interpreted the patient's clinical data. BAS, ASK and MPL provided critical revision of manuscript. All named authors take responsibility for the integrity of the work and give their approval for the final manuscript for publication.

\section{References}

1. Spaide RF, Campeas L, Haas A, Yannuzzi LA, Fisher YL, et al. (1996) Central serous chorioretinopathy in younger and older adults. Ophthalmology 103: 2070-2079. [Crossref]

2. Daruich A, Matet A, Dirani A, Bousquet E, Zhao M, et al. (2015) Central serous chorioretinopathy: Recent findings and new physiopathology hypothesis. Prog Retina Eye Res 48: 82-118. [Crossref]

3. Robertson DM, Ilstrup D (1983) Direct, indirect, and sham laser photocoagulation in the management of central serous chorioretinopathy. Am J Ophthalmol 95: 457-466.

4. Steinle NC, Gupta N, Yuan A, Singh RP (2012) Oral rifampin utilisation for the treatment of chronic multifocal central serous retinopathy. Br J Ophthalmol 96: 10-13. [Crossref]

5. Spitznas M, Huke J (1987) Number, shape, and topography of leakage points in acute type I central serous retinopathy. Graefes Arch Clin Exp Ophthalmol 225: 437-440. [Crossref]

6. Turchetti R, de Moraes HV Jr, Maia HS (2005) Number, shape, and topography of leakage points in patients with central serous chorioretinopathy. Arq Bras Oftalmol 68: 317-320. [Crossref]

7. Haimovici R, Koh S, Gagnon DR, Lehrfeld T, Wellik S (2004) Central serous chorioretinopathy case-control study group. Risk factors for central serous chorioretinopathy: a case-control study. Ophthalmology 111: 244-249.

8. Liu B, Deng T, Zhang J (2016) Risk factors for central serous chorioretinopathy: A systematic review and meta-analysis. Retina 36: 9-19. [Crossref] 
9. Mansour AM, Koaik M, Lima LH, Casella AMB, Uwaydat SH, et al. (2017) Physiologic and psychologic risk factors in central serous chorioretinopathy. Ophthalmol Retina 1 : 497-507.

10. Zavoloka O, Bezditko P, Lahorzhevska I, Zubkova D, Ilyina Y (2016) Clinical efficiency of Helicobacter pylori eradication in the treatment of patients with acute central serous chorioretinopathy. Graefes Arch Clin Exp Ophthalmol 254: 1737-1742. [Crossref]

11. Schwartz R, Habot-Wilner Z, Martinez MR, Nutman A, Goldenberg D, et al. (2017) Eplerenone for chronic central serous chorioretinopathy-a randomized controlled prospective study. Acta Ophthalmol 95: e610-e618. [Crossref]

12. Auguste P, Tsertsvadze A, Pink J, Court R, McCarthy N, et al. (2017) Comparing interferon-gamma release assays with tuberculin skin test for identifying latent tuberculosis infection that progresses to active tuberculosis: systematic review and meta-analysis. BMC Infect Dis 17: 200. [Crossref]

13. Vayalambrone D, Ivanova T, Misra A (2012) Atypical central serous retinopathy in a patient with latent tuberculosis. BMJ Case Rep. [Crossref]

14. Ravage ZB, Packo KH, Creticos CM, Merrill PT (2012) Chronic central serous chorioretinopathy responsive to rifampin. Retina Cases Brief Rep 6: 129-132. [Crossref]

15. Khan P, Khan L, Anjum N, Saxena N (2017) Central serous chorioretinopathy secondary to tuberculosis: cause or coincidence. BMJ Case Rep. [Crossref]

16. Bajgai P, Sharma K, Bansal R, Gupta N, Sharma A, et al. (2016) Detection of Mycobacterium tuberculosis genome in subretinal fluid of patients with latent tuberculosis infection. Ocul Immunol Inflamm 24: 615-620.

17. Biswas J, Kazi MS, Agarwal VA, Alam MS, Therese KL (2016) Polymerase chain reaction for Mycobacterium tuberculosis DNA detection from ocular fluids in patients with various types of choroiditis in a referral eye center in India. Indian J Ophthalmol 64: 904-907. [Crossref]

18. Nazari H, Karakousis PC, Rao NA (2014) Replication of Mycobacterium tuberculosis in retinal pigment epithelium. JAMA Ophthalmol 132: 724-729. [Crossref]

19. La Distia Nora R, Walburg KV, van Hagen PM, Swagemakers SMA, van der Spek PJ, et al. (2018) Retinal pigment epithelial cells control early Mycobacterium tuberculosis infection via interferon signaling. Invest Ophthalmol Vis Sci 59: 13841395. [Crossref]
20. Zhang Y, Doerfler M, Lee TC, Guillemin B, Rom WN (1993) Mechanisms of stimulation of interleukin-1 beta and tumor necrosis factor-alpha by Mycobacterium tuberculosis components. J Clin Invest 91: 2076-2083. [Crossref]

21. Keane J, Balcewicz-Sablinska MK, Remold HG, Chupp GL, Meek BB, et al. (1997) Infection by Mycobacterium tuberculosis promotes human alveolar macrophage apoptosis. Infect Immun 65: 298-304. [Crossref]

22. Bagheri M, Rashe Z, Ahoor MH, Somi MH (2017) Prevalence of Helicobacter pylor infection in patients with central serous chorioretinopathy: A Review. Med Hypothesis Discov Innov Ophthalmol 6: 118-124. [Crossref]

23. Giusti C (2004) Association of Helicobacter pylori with central serous chorioretinopathy hypotheses regarding pathogenesis. Med Hypotheses 63: 524-527. [Crossref]

24. Langford MP, Chen D, Gosslee J, Misra RP, Redens TB, et al. (2006) Intracameral toxicity of bacterial components muramyl dipeptide and staurosporine: ciliary cyst formation, epithelial cell apoptosis and necrosis. Cutan Ocul Toxicol 25: 85-101. [Crossref]

25. Zhang M, Zhang J, Liu Y (2012) Clinical presentations and therapeutic effect of presumed choroidal tuberculosis. Retina 32: 805-813. [Crossref]

26. Albert DM, Raven ML (2016) Ocular tuberculosis. Microbiol Spectr 4: 10. [Crossref]

27. Goldstein BP (2014) Resistance to rifampicin: a review. J Antibiot 67: 625-630. [Crossref]

28. 'Steingart KR, Schiller I, Horne DJ, Pai M, Boehme CC, et al. (2014) "Xpert ${ }^{\circledR}$ MTB RIF assay for pulmonary tuberculosis and rifampicin resistance in adults". Cochrane Database Syst Rev: CD009593. [Crossref]

29. Atik A, Hu Y, Yu H, Yang C, Cai B, et al. (2017) Changes in macular sensitivity after half-dose photodynamic therapy for chronic central serous chorioretinopathy. BMC Ophthalmol 17: 140. [Crossref]

30. Mattingly JJ, Amram AL, El-Annan J (2018) Low-dose rifampin in chronic central serous chorioretinopathy. Can J Ophthalmol 53: e182-e183.

31. Edwards OM, Courtenay-Evans RJ, Galley JM, Hunter J, Tait AD (1974) Changes in cortisol metabolism following rifampicin therapy. Lancet 2: 548-551. [Crossref]

32. Wehrli W (1983) Rifampin: mechanisms of action and resistance. Rev Infect Dis 5 Suppl 3: S407-S411

Copyright: (C2020 Kavanaugh AS. This is an open-access article distributed under the terms of the Creative Commons Attribution License, which permits unrestricted use, distribution, and reproduction in any medium, provided the original author and source are credited. 